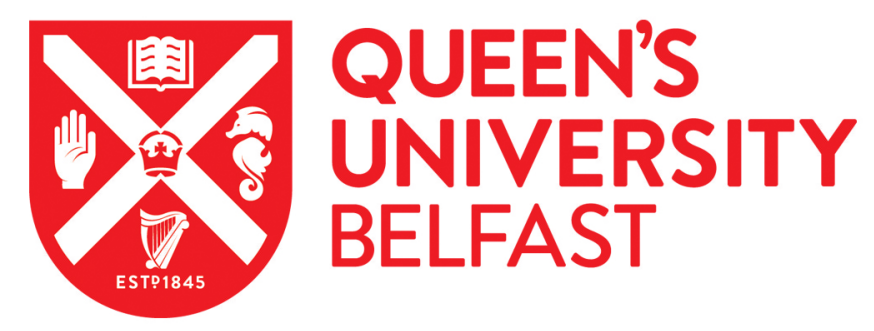

\title{
Embracing error
}

Conn, R. (2018). Embracing error. The Clinical Teacher, 15(2), 180. [2]. https://doi.org/10.1111/tct.12748

\author{
Published in: \\ The Clinical Teacher
}

Document Version:

Peer reviewed version

Queen's University Belfast - Research Portal:

Link to publication record in Queen's University Belfast Research Portal

Publisher rights

Copyright 2018 Wiley. This work is made available online in accordance with the publisher's policies. Please refer to any applicable terms of use of the publisher.

\section{General rights}

Copyright for the publications made accessible via the Queen's University Belfast Research Portal is retained by the author(s) and / or other copyright owners and it is a condition of accessing these publications that users recognise and abide by the legal requirements associated with these rights.

Take down policy

The Research Portal is Queen's institutional repository that provides access to Queen's research output. Every effort has been made to ensure that content in the Research Portal does not infringe any person's rights, or applicable UK laws. If you discover content in the Research Portal that you believe breaches copyright or violates any law, please contact openaccess@qub.ac.uk. 


\section{Embracing error}

Richard L Conn

Centre for Medical Education, Queen's University Belfast, Belfast, United Kingdom

E-mail: r.conn@qub.ac.uk 
Besides its harmful effects on patients, medical error can be psychologically disastrous for doctors. Yet, in the right circumstances, error can precipitate personal reflection, development and growth. The following recently-published articles use varied methodologies and disciplinary perspectives to explore how error can drive learning.

It seems intuitive to teach health professions students to avoid errors. In their novel study, Dyre et al ${ }^{1}$ explore a contrasting approach - encouraging students to make mistakes. They randomised medical students learning foetal ultrasound to either error management training (EMT), or error avoidance training (EAT). Students in the EMT group were instructed to deliberately make errors, whereas their peers were told to commit as few as possible. After training, they found that post-test classroom performance was similar, but EMT students performed significantly better when practising the skill on patients 7-10 days later. The authors propose that EMT students developed a deeper understanding by 'actively exploring and positively framing errors'. EAT students, by contrast, had been 'relatively protected from experiences of difficulties and complexity during training'. The authors acknowledge the ultimate need to minimise errors, but contend that 'novice learners may benefit from imperfect practice as a means to achieving perfect practice'.

Of course, making a mistake in the relative safety of undergraduate education is a far cry from doing it in practice. Plews-Ogan et $\mathrm{a}^{2}$ interviewed 61 doctors to explore how they had recovered after making an error. They argued that studying those who developed 'wisdom' after error could give insight into circumstances which enable positive recovery. 'Wisdomexemplars' were identified by analysis of interview transcripts guided by a psychological model. They found that these wisdom-exemplars were almost twice as likely to have 
disclosed their error to the patient. An important criticism of this finding is that qualities used to define wisdom - such as compression and empathy - are similar to those which might lead to disclosure. However, subsequent qualitative analysis also supported the key role of disclosure and apology, suggesting these were 'critical first steps toward the possibility of healing a broken relationship and being able to deal openly with the event'. The authors conclude by calling for changes to redefine medical culture to foster circumstances which promote growth, not just recovery, after error.

What stops doctors from disclosing errors? In their review, Han et $\mathrm{al}^{3}$ used social psychology - which explores intersections between thought and behaviour - to analyse influences on how physicians act. They argue that two cognitive biases hinder disclosure. Fundamental attribution error is the tendency to overestimate personal role over context - humans prefer stories in which outcome depends on individuals, not circumstances. Clearly this bias is at odds with medical error, which almost always arises from multiple human mistakes within flawed systems. Secondly, forecasting error is 'the tendency to overestimate the impact or duration of the negative consequences of failure'; in other words, doctors may not think recovery possible after serious error, and this in turn may inhibit disclosure. The authors offer practical ways to enable doctors to recognise and overcome intrinsic biases, such as designing simulated patient encounters that evoke psychosocial elements of error disclosure.

Barriers to error disclosure are as much cultural as individual, however. Langer et al's ${ }^{4}$ refreshing approach to this involved flipping traditional roles by engaging patients and families to co-design and lead a new education programme, 'Patient-Teachers in Patient 
Safety'. Clinicians from a wide range of professional backgrounds were invited to participate. They attended workshops which included live simulation of a medical error disclosure, discussion of 'speaking up' opportunities, and a forum for participants to commit to practice changes. For evaluation, the authors used a mixed methods approach with baseline and postintervention surveys. They found that, despite initial concerns about power dynamics and defensiveness, nearly all participants found the collaborative learning model valuable. Clinicians valued discussing 'areas of mutual vulnerability', while patients appreciated seeing the emotional impact that errors have on clinicians. The authors conclude that shared learning can help patients and clinicians to understand each other's perspectives, promoting greater cultural transparency.

Together, these articles show that error can be used as a powerful tool for learning, both in the relative safety of the classroom, and in practice, where they occur despite best efforts. But they also highlight that its learning potential hinges on attitudes and culture. How can educators embrace error, and drive cultural change? Encourage active exploration of errors in training. Proactively teach about discussing errors with both patients and peers. Advocate for ways to overcome barriers to disclosure, both psychological and cultural. Involve patients and families as partners in education. Error will always have negative effects, but these strategies can help educators realise its learning potential.

\section{References}

1. Dyre L, Tabor A, Ringsted C, Tolsgaard MG. Imperfect practice makes perfect: error management training improves transfer of learning. Med Educ. 2017;51(2):196-206. 
doi:10.1111/medu.13208.

2. Plews-Ogan M, May N, Owens J, Ardelt M, Shapiro J, Bell SK. Wisdom in Medicine. Acad Med. 2016;91(2):233-241. doi:10.1097/ACM.0000000000000886.

3. Han J, Lamarra D, Vapiwala N. Applying lessons from social psychology to transform the culture of error disclosure. Med Educ. 2017:51(10):996-1001. doi:10.1111/medu.13345.

4. Langer T, Martinez W, Browning DM, Varrin P, Sarnoff Lee B, Bell SK. Patients and families as teachers: a mixed methods assessment of a collaborative learning model for medical error disclosure and prevention. BMJ Qual Saf. 2016;25(8):615-625. doi:10.1136/bmjqs-2015-004292. 